\title{
Foreignization of Tao Te Ching Translation in the Western World
}

\author{
Yuan Tao \\ School of Foreign Languages, Dalian University of Technology, China \\ Fengjun $\mathrm{Yu}$ \\ School of Foreign Languages, Dalian University of Technology, China
}

\begin{abstract}
As one of the philosophical gem of China, Tao Te Ching is the most-translated Chinese classic. A translator has to face the dilemma of domestication and foreignization when dealing with the oriental language style. Retaining the culture and strangeness of the target language, the foreignized translation reflects the respect for the source language and culture, which has become the trend for translation. The quantitative analysis on the basis of 55 authoritative translation versions of Tao Te Ching indicates the foreignization in phonetics, image and structure, which is the promotion of many new expressions and multicultural merge.
\end{abstract}

Index Terms - foreignization, phonetics, image, structure, alterity

\section{INTRODUCTION}

As the first philosophical classic in China with its laconic language and profound insight, Tao Te Ching has attracted numerous scholars and philosophers to translate the book. With the profound Taoism and man y Chinese culture-specific items, it has been translated into many languages and aroused the attention and interest all over the world. It is an issue worth studying concerning whether the translator should adopt domestication or foreignization to stress similarities or dis similarities in terms of the cultural connotation.

\section{FOREIGNIZATION}

The concept of foreignization and domestication orig inate from On the Different Methods of Translation, a speech by Friedrich Schleiermacher, the German theologian and philosopher who suggests two roads of translation: "Either the translator leaves the author in peace, as much as possible, and moves the reader toward him. Or he leaves the reader in peace, as much as possible, and moves the author toward him." (André Lefevere, 1992) And he personally prefers the first approach through which the translator will retain the strangeness and transplant the foreign flora so that "the readers can enjoy the same pleasure he himself has, with the traces of hardship it carries and the feeling of strangeness that remains mixed into it" (p.147).

A century later, Antoine Berman (1992), the French translator and theorist discusses the foreignization from the theoretical level and terms the "fidelity" as the ethics of translation. He argues that the very essence of translation is not only the conveyance or restatement of the information, but also "a dialogue, a crossbreeding, a decentering" (p.4). He criticizes the so-called "naturalization" and states that the translation should accept and respect the foreigness to avoid repressing the individuality in literature as translation is a place for cultural alterity.

In 1995, Lawrence Venuti presents the concept of “domestication and foreignization" in The Translator's Invisibility for the first time on the basis of the dualism of Schleiermacher, the autonomy of translation of Ezra Pound and the abusive fidelity of P. Lewis. Domestication and foreignization are two translationstrategies, regarding the degree to which translators make a text conform to the target culture. Domestication is the strategy of making text closely conform to the culture of the language being translated to, which may involve the loss of information from the source text. Foreignization is the strategy of retaining information from the source text, and involves deliberately breaking the conventions of the target language to preserve its meaning.

Venuti(1995) cites Norman Shapiro's metaphor of "a pane of glass" to describe the translation with little imper-fections like scratches and bubbles. He disagrees with the translation without any linguistic or stylistic peculiarities and calls the "invisibility of the translator" a weird self-annihilation. The illusion of transparency covers up "the crucial intervention" of the orig inal text. Venuti proposes the resistant strategy to preserve the difference and the otherness and challenge the aesthetic culture of the target language (p.306). In 1998, he goes further and claims the translation catering to the target language blindly as a scandal and explains his preference of minoritizing translation in which he suggests the translator manifest the foreigness of the foreign text to avoid the inequality in translation (Venuti,1998).

The kernel idea of foreignization is to manifest the linguist and cultural dissimilarities in the source language and 
resist the ethnocentric value for the promotion of the crossbreeding and assimilation of the two cultures. It can cultivate the heterogeneous discourse, open up the standard dialect and literary canons to form sociolect, creative style and cultural renovation. In the cross-cultural communication, translators of the classics have to face the dilemma of domestication or foreignization. The choice of either approach is a reflection of the translator's attitude towards the individuality of the source culture. The respect, emphasis and preservation of the differences are the highlight of Venuti's ideas. As a result, the foreigness and alterity in classic translation are also a reflection of the respect for the source culture and the classics.

\section{TRANSLATION OF TAO TE CHING IN THE WEST}

Tao Te Ching has 81 chapters in two parts, the Tao Ching (chaps. 1-37) and the Te Ching (chaps. 38-81) with brief and ambiguous wording which encourages various interpretations. As a gem of oriental wis dom, Tao Te Ching has great influence in the world. According to the statistics of Knut Walf from University of Nijmegen in 1989, Tao Te Ching has 252 versions in 17 European languages from 1816 to 1988, which is the most translated Chinese classics and lists only next to the Bible among all the translated world literature. Holmes Welch (1965), the professor from Harvard University says that the book is a famous puzzle which everyone would like to feel he had solved.

Tao Te Ching has been translated into many Western languages, mostly to English, German, and French. Among all these translated versions, the English ones top the list. Since John Chalmers, the English missionary translated the book into English in 1868, many scholars have tried to translate and interpret the book. In history, there appeared three stages of translating Tao Te Ching. The first one started from 1868 to 1905 when most of the translators were English Congregationalists including the most noted one, James Legge whose version is most faithful and rigorous. The second tide is from 1934 to 1963 when many sinologists such as Arthur Waley and Witter Bynner translated the book. In 1973, the unearthing of two original silk texts of the Tao Te Ching in Ma-Wang-Tui tomb aroused the third tide of trans lation when many Chinese and foreign scholars cooperated to translate the book. In this period, the versions of D. C. Lau, Victor H. Mair and Robert G Henricks are the most influential. Since 1990s, the enthusiasm for the translation of Tao Te Ching has showed no signs of decreasing and an average of 4.6 English versions of Tao Te Ching has been published each year. The versions by Thomas Cleary (1991), Michael Lafargue(1992) and A. S. Kline (2003) are comparatively renowned. Till now there are over 180 English versions of the classic and it can be expected that the figure will still climb in the future.

Many Chinese and western scholars have studied the English versions of Tao Te Ching. Wang Rongpei (1992) elaborates "Tao", the abstract keyword with profound meanings. Erin M. Cline (2004) discusses two interpretations of De in Daodejing. Feng Xiaoli (2009) analyzes the version of D. C. Lau. Yoav Ariel and Gil Rez (2010) explains the adoption of anaphor or cataphor of qi (其) in the fist chapter of the book. However, the study on the foreignization of the book has been rare. The paper has an analysis and comparis on of the domestication of foreignization of Tao Te Ching on the basis of 55 authoritative English versions by the noted translators such as James Legge, Arthur Waley, Lionel Giles, A leister Crowley, Gia-Fu Feng \& Jane English, Robert G Henricks, and Stephen Mitchell etc.

\section{FOREIGNIZATION OF TAO TE CHING}

As the earliest book of Taois m, Tao Te Ching is fundamental to the philosophical Tao ism and enjoys authoritative status in Chinese culture. It has strong influence over other schools such as Legalis $m$ and has been the inspiration for many Chinese artists, painters, and poets. The total domestication of the translation may result in misinterpretation and misreading as the "foreignness" in the source text may be weakened or even removed and canon requires classic elaboration of book. The foreignized translation tends to incorporate foreign elements in the target language to retain the source language and culture. The foreigness is reflected in many levels such as phonetics, vocabulary, grammar, style, value, power-d iscourse, and ideology. The closer the translation is to the orig inal te xt, the more foreigner it shows. This paper discusses the foreignization in phonetic level, cultural image and discourse structure in the translation of Tao Te Ching.

\section{A. Phonetic Foreignization}

Among all the nine schools (Confucianism, Mohism, Taois m, Legalism, Logicians, Eclectics, Agriculturists, Yin - Yang School and Diplomatists) founded by Pre-Qin scholars, only Confucianis m, Mohis m, Taois m and Yin-Yang School adopt phonetic translation because of the lack of equivalents in English. Tao appeared in I Ching and Zuo Zhuan with the meaning of road or principle. Lao Tzu proposed Tao as the orig in of the world for the first time as the essence of Taois mand the kernel concept of his philosophy. In the very beginning of the book, Lao Tzu says, "The Tao that can be told is not the invariant Tao/the names that can be named are not the invariant Names." (tr. Michael LaFargue, 1992) The metaphysical concept of Tao is the origin of the Universe and all existence, an abstract absolute and the unlimited being. Invisible as it is, it is omnip resent in the universe with the nature of nihility and inactivity.

As a kernel category with various levels and structures in Chinese philosophy, Tao (Zhang Liwen, 1989) can be summarized with eight connotations: 1) Way or rules; 2) origin of the universe; 3) one; 4) nihility; 5) Taichi; 6) mind; 7) chi; 8) humane. In other words, Tao can be elaborated as the origin of nature, rules, movement process, and the way of 
politics and ruling the country. It appears 74 times in 37 chapters of the book with various meanings. According to the 55 authoritative English versions of Tao Te Ching, we can find that the main translation of the word as follows:

TABLE 1 .

THETRANSLATION OFTAO ANDTHEPERCENTAGE IN TAO TE CHING

\begin{tabular}{l|l|l|l|l}
\hline Translation of Tao & Tao & Dao & Way & existence, nat ure, origin, guide, principle \\
\hline Number & 30 & 5 & 15 & 5 \\
\hline Percentage (\%) & 54.5 & 9.1 & 27.3 & 9.1 \\
\hline
\end{tabular}

As listed in Table 1, about $54.5 \%$ of the trans lators such as James Legge, Stephen Mitchell, and John C. H. Wu adopt foreignization in phonetics, i. e. Tao to express the abstract word. In 1796, Tao is collected by the Oxford Dictionary with three connotations. Tao and its derivatives such as Taois $\mathrm{m}$ and Tao ist have been collected and well-established in many authoritative dictionaries such as Webster, Longman and Cambridge. In the $21^{\text {st }}$ century, many translators such as Nina Correa use piny in of Dao originated in the mid $-20^{\text {th }}$ century but Dao has not been collected by other dictionaries except Cambridge. Some translators such as Arthur Waley, D. C. Lau, and Robert G Henricks translate the word as "the way" while some use existence, nature and spirit etc.

Tao--the nameless and ineffable word of oriental mysticism is used frequently in the book. Neither the word of "way, path, or road" nor the expressions of "existence or spirit" can fully describe the nature of Tao. The fore ignization in phonetics can inspire the interest and curiosity of the audience by conveying the word in phonetics, semantics and culture. Moreover, many translators adopt phonetic foreignization in the translation of the words with cultural connotations such as Te, Chi, Tien, and wu-wei which expand the English vocabulary and convey the key words of oriental culture directly.

\section{B. Foreignization in Images}

Word, image and the meaning constitute the major elements of literature. As the raw material of thought and the vehicle of meaning, image includes all the subjects in nature except human beings. It is used to express the abstract concept and philosophical ideas with the combination of the subjectivity and objectivity and the author's emotion and the scenery. Based on the emotion, image has been considered as an important aesthetic category in the Chinese culture. The adoption of image can be dated back to I Ching, "Image can be used by the sage to express what can not be fully stated." In Han dynasty, Liu Xie proposes that images of all subjects should be mixed with the author's spiritual activities in his book Dragon-Carving and the Literary Mind. The images originate from the subjects of the world but are not limited to the subjects. Instead, they carry what the author wants to exp ress by vivid illustrations.

In the western world, image orig inates fro m "imago" in Latin which is an important way to elaborate and analyze the poems and poetic dramas. Sir Philip Sydney says that "imaging is itself the very height and life of poetry." Arthur Waley holds that imagery is the soul of poetry. In the end of the seventeenth century, the English philosopher Thomas Hobbes emphasizes that the origin of all thought is sensation, which consists of mental images produced by the pressure of motion of external objects. Thus Hobbes anticipated that these sense images are extended by the power of memory and imagination. Later, John Dryden, the English literary critic applies image into poem criticism for the first time. In the $20^{\text {th }}$ century, T. E. Hume, the English critic and poet and Ezra Pound, the American poet launched the imagist movement in which clear, specific and concrete images are called for and image has been enhanced to an unprecedented height. In a word, image is the perceptual form of subject on the bas is of the objective world and the sensation of the author.

Tao Te Ching is a classical poem of philos ophy with rhy med three-word or four-word sentences and occasional loose sentences. Lao Tzu elaborates his abstract ideas with the application of 23 original and apt images such as water, valley streams, bellow, straw dogs, jade and stone etc, which make the profound philosophy plain and vivid. The major images and the foreignization are as shown in following table:

TABLE2.

FOREIGNIZATION OF IMAGES ANDTHE PROPORT ION IN TAO TE CHING

\begin{tabular}{l|l|l|l|l|l|l|l|l}
\hline Image & water & bellows & straw dogs & gold \& jade & baby & feast & uncarved wood & small fish \\
\hline Number & 55 & 48 & 42 & 40 & 54 & 43 & 49 & 51 \\
\hline Proportion (\%) & 100 & 87 & 76 & 72 & 98 & 78 & 78 & 92 \\
\hline
\end{tabular}

In dealing with the common and similar images, most Chinese and western translators adopt the original images of the author. For example, in the eighth chapter, the author takes the water as a metaphor to express his yielding, void and tranquil outlook of the world and his “female” value:上善若水，水善利万物而不争.(Pinyin: Shangshan ruo shui, shui shan li wanwu er buzheng.) The omnipresent water contributes to all living things in the world. It is appropriate and natural to describe the highest goodness with the nutritious water which never makes a display of itself becau se the readers can understand easily and clearly what the supreme goodness is by the image popular home and abroad. In the 55 authoritative English versions such as James Legge and Victor H. Mair, all the translators adopt the original image by Lao Tzu unanimously and translate the sentence as: The highest excellence is like that of water. (tr. James Legge) or The highest good is like water. (tr. Victor H. Mair) 
Accepted by both eastern and western cultures, the image of water transcends the limitation of time and space with its characteristics of all-inclusiveness, mo isture, softness, flexibility and invincibility which reflect the nature that "the way of heaven is conditioned by those of Tao and the ways of Tao by Self-so." (tr. Arthur Waley)

Moreover, in dealing with the unique image loaded with Chinese culture, most translators adopt the original images as well. Take a sentence in the fifth chapter: 天地不仁, 以万物为刍狗(Pinyin: Tiandi buren, yi wanwu wei chugou) as an example. In ancient China, chugou (straw dog) is the sacrifice which the author uses to describe the worthless and useless things or opinions. In the 55 English versions, some translators use the ambiguous "sacrificial images", or domesticate it as guinea pigs, grasses of field, or used talis mans which are more easily for the western readers to understand, or even cancel the images. However, most versions adopt straw dogs directly or amplify the cultural connation as sacrifice of straw dogs (Witter Bynner, 1944), offering straw dogs (Tolbert McCarroll, 1982) and ritual straw dogs (Tormond Byrn, 1997), which fully express the loaded cultural connotation.

In the $60^{\text {th }}$ chapter, “治大国若烹小鲜(Pinyin: Zhi daguo ruo peng xiaoxian)” is also an ingenious image by Lao Tzu. Apart from D. Allchin who translates it into "like crystal handle with care", all the other scholars translate it into "Ruling/Governing a big country is like cook/fry/boil small fish". Besides, many translators adopt the creative and imaginative metaphors and images in Chinese culture such as "a house full of gold and jade", "He who lives in Mergence with Great Te is pure like a newborn baby". The witty images comb ine the abstract ideas and concrete objects, the author's spirit and emotion, the reasoning and the imagination skillfully. Natural and fluent as the domesticated versions are, the linguistic and cultural features behind the source language vanish in the seemingly transparent translation while the foreignized text reflects the original and unique expressions which impress the target language readers with unusual inspiration.

\section{Foreignization in Structure}

Besides the profound ideas and the succinct languages, the structure of the text is also distinctive with the rhetorical device of anadiplosis which indicates the continuous or progressive relations with the repetition of the last word of the previous line. In Systemic-functional Grammar, the thematic progression is termed Linear Progression in which something introduced as new information in the Rheme of the first clause is taken up to be the Theme of the second.

Although thematic progressions are still controversial in the field, they are generally classified into five basic types of constant theme, constant rheme, linear progression, derived theme and split rheme. The quantitative analysis based on Tao Te Ching show that Linear Progression amounts to $40 \%$ among all the five thematic progressions, which is a striking feature in the structure of the book.

Language aims at conveying information and each information unit is a structure composed of two parts: the Given and the New. In most cases, the theme is the Given and heme the New. The sentence structure highlights the progressive relationship with given information carrying the new information which is transferred into theme for the given in the next sentence. The spiral structures form a complete and cohesive information chain and strong rhythm to convey the continuous and progressive relationships.

The structure is plentiful in the book such as in 25, 37, 42, 59, and 61chapters and all together there are 23 anadiplosis structures in Tao Te Ching which are very impressive to the audience such as "The Tao formulated the One. /The One exhaled the Two./ The Two were parents of the Three./ The Three were parents of all things" (42 Chapter) etc.

Many translators follow the oriental winding structure in Chinese to retain the classical Chinese thinking mode. For example, Victor H. Mair translates the four anadiplosis in the $25^{\text {th }}$ chapter as follows:

人法地, Man patterns himself on earth,

地法天， Earth patterns itself on heaven,

天法道， Heaven patterns itself on the Way,

道法自然。 The way patters itself on nature.

His version retains the original Chinese structure, which reflect the rhyth $m$ and structure of the classical Ch inese. The foreignized translation is similar to the original te xt in form, which retains the Chinese linguistic structure and original style to the maximum vividly. The audience of target language has an understanding of the special expression of Chinese.

What's more, hypotaxis and parataxis are two ways to connect sentences in all languages. It is agreed that English is more hypotactic while Chinese more paratactic. Nida remarks in his Translating Meaning (1983) that the most important difference in linguistics between English and Chinese is the contrast of hypotaxis and parataxis. In Chinese, language cohesion does not lie in form but in covert cohesion and the logical meaning of the words or phrases. Tao Te Ching is written in classical Chinese which is more concise with few grammat ical particles and conjunctives. The passage in the first chapter is very brief with no verbs:无名, 天地之始。有名, 万物之母。故常无欲, 以观其妙。 常有欲, 以观其徼. As a hypotactic language, English often resorts to overt cohesion, frequently using various cohesive ties such as coordinators, subordinators, relative pronouns and adverbs, prepositions etc. however, Ellen Marie Chen, the American Chinese translator imitates the original Chinese structure in the following way:

Nameless (wu-ming), the origin of heaven and earth; /Named (you-ming), the mother (mu) of ten thousand things. Therefore, always (ch'ang) without desir e(wu-yü), /In order to observe(kuan) the hidden mystery (miao); /always (ch'ang) with desire(you- yü), /In order to observe the manifestations (chiao). (tr. Chen,1989:3) 
Similarly, 9.1\% translators such as Herry mon Maurer (1985), Stephen Addiss (1993), Stanley Lombardo(1993), Tim Chilcott (2005) and Aalar Fex (2006) preserve the Chinese structure without using verbs in English as well. The compact language embodies the poetic structure, which produces the novelty and strangeness resulting from the mixture, compromise and blending of different cultures. It is also worth noting that foreignized translation is the purposeful recreation of the orig inal characteristics and the intention of the author on the premise of a new readability and smoothness instead of the pidgin or the grotesque and confusing translation.

\section{CONCLUSION}

Tao Te Ching attracts numerous scholars to introduce the profound insights with its unique cultural and linguistic features. The translation versions are varied in content as some translators distort the meaning for the sake of form or rhymes, or amplify the subtitles in the chapters on the basis of their understanding, or change the original images to cater for the value and culture of the target language, which lead to the misunderstanding of the book in the western world.

From the dynamic equivalence by Eugene Nida (1964), the skopos theory by Hans J. Vermeer (1987), and the manipulation of culture by Andre Lefevere (1990) to the foreignization by Lawrence Venuti (1995), it is the reversion from the TL-oriented translation to the SL-oriented translation. In the conflict and collision between the two cultures, the foreignized translation reflects mutual in filtration and exchange of different languages and cultures on the basis of the equality of different cultures. It is of great help to deal with the difference in the source language and target language, to cultivate the source culture in the totally different soil of target language.

\section{REFERENCES}

[1] Ariel, Yoav and Gil Rez. (2010). Anaphors or Cataphors? A Discussion of the Two Qi (其) Graphs in the $1^{\text {st }}$ Chapter of Daodejing. Philosophy East and West, 60, 391- 421.

[2] Berman, Antoine. (1992). The Experience of the Foreign: Culture and Translation in Romantic Germany. Albany: State University of New York.

[3] Chen, Ellen M. (1989). The Tao Te Ching. New York: Paragon House.

[4] Cline, M. Erin. (2004). Two Interpretations of De in Daodejing. Journal of Chinese Philosophy, 31, 219-233.

[5] Feng Xiaoli. (2009).An Analy sis of D. Lau's Translation of Tao Te Ching. Sichuan International Studies University Journal, 25, 85-88.

[6] Lefevere, André. (2004). Translation/History/Culture-A Sourcebook. Shan ghai: Shan ghai Foreign Language Education Press.

[7] Legge, James. (2008). The Analects of Confucius, A Selection of the Sayings of Mencius, and The Way and Its Power of Laozi. East Bridgewater: World Publications Group.

[8] Nida, E. A. (1982). Translating Meaning. San Dimas, California: English Lan guage Institute.

[9] Venuti, Lawrence. (1995). The Translator's Invisibility. London: Routledge.

[10] Venuti, Lawrence. (1998). The Scandals of Translation. London: Routled ge.

[11] Waley, Arthur. (2009). Tao Te Ching. Beijing: Foreign Lan guage Teaching and Research Press.

[12] Wang Rongpei. (1992). Translation Can Be Defined, But It Is Not the Eternal One. Foreign Languages and Their Teaching, 25-30.

[13] Welch, Holmes. (1965).Taoism: The Parting of the Way. Boston: Beacon Press.

[14] Zhang Liwen. (1989). Tao. Beijing: Renmin University of China Press.

[15] Hobbes, Thomas. (2012). http://www.notablebiographies.com/He-Ho/Hobbes-Thomas.html (accessed 22/5/2012).

[16] http://wayist.org/ttc\%20compared/all_translations.htm (accessed20/9/2012)

[17] http://www.dmoz.org/Society/Religion_and_Spirituality/Taoism/Texts/Tao_Te_Ching/(accessed20/9/2012)

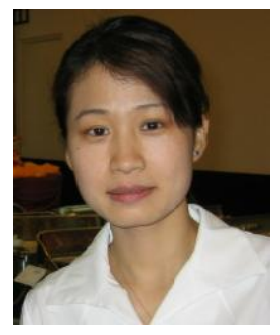

Yuan Tao, born in Haerbin, Heilongiang province in 1975, is a lecturer in the School of Foreign Languages at Dalian University of Technology. Main areas of her expertise include translation studies, linguistics and applied linguistics, content-based instruction in teaching.

She has taught English for nearly a decade and her representative publications include Translation of Constant Rheme Progression in Mencius, Thematic Progression in EST and the Translation, Application of Antithesis in English-Chinese Translation from Functionalist Translation Theory etc., and she also published and translated several books.

Fengjun Yu, born in Dalian, Liaoning province in 1967, is an associate professor in the School of Foreign Languages at Dalian University of Technology. Main areas of her expertise include translation studies and classics translation into English.

Her representative publications include Social Semiotics' Guidance on Translation Practice and On Second Language Learning Strategies and Teaching of Listening etc., and she also published and translated several books. 